\title{
ESTIMASI NILAI EKSTERNALITAS KONVERSI HUTAN MANGROVE MENJADI PERTAMBAKAN DI DELTA MAHAKAM KABUPATEN KUTAI KARTANEGARA
}

\section{Estimating of Externality Value Conversion Mangrove Forest into Shrimp Pond in Mahakam Delta District of Kutai Kartanegara}

\author{
Yunianto Setiawan $^{1}$, Dietriech G. Bengen ${ }^{2}$, Cecep Kusmana ${ }^{3}$, dan Setyo Pertiwi ${ }^{4}$ \\ ${ }^{1}$ Program Studi Teknik Lingkungan, Fakultas Teknik, Universitas Mulawarman \\ Kampus Gunung Kelua J1. Kuaro, Samarinda 75119, Kalimantan Timur, Indonesia \\ Telp. +62-541-736834; Fax. +62-541-749315 \\ ${ }^{2}$ Departemen Ilmu dan Teknologi, Fakultas Perikanan dan Ilmu Kelautan, Institut Pertanian Bogor \\ Jl. Lingkar Kampus IPB, Dramaga Bogor 16680, Jawa Barat, Indonesia \\ Telp. +62-251-8622909; Fax. +62-251-8622907 \\ ${ }^{3}$ Departemen Silvikultur, Fakultas Kehutanan, Institut Pertanian Bogor \\ Jl. Lingkar Kampus IPB, Dramaga Bogor 16680, Jawa Barat, Indonesia \\ Telp. +62-251-8626806; Fax. +62-251-8626886 \\ ${ }^{4}$ Departemen Teknik Mesin dan Biosistem, Fakultas Teknologi Pertanian, Institut Pertanian Bogor \\ Telp. $+62-251-8623026$ \\ Jl. Lingkar Kampus IPB, Dramaga Bogor 16680, Jawa Barat, Indonesia \\ Email: wansety@yahoo.com¹,ckusmana@ymail.com³
}

Tanggal diterima: 27 November 2014; Tanggal direvisi: 23 Oktober 2015; Tanggal disetujui: 11 November 2015

\begin{abstract}
Benefit decreation of mangrove ecosystem is directly or indirectly caused by conversion of mangrove forest into ponds. Sylvofishery system was performed to rehabilitate the ecosystem. This study aimed to estimate the externality values of mangrove areas converted to ponds in the Mahakam Delta and to conduct financial analysis of traditional extensive system as well as sylvofishery system. The study concluded that the lost benefit value was up to Rp 209,688,551,071/year from 75,311 ha converted mangrove forests to ponds. Traditional extensive pond system had negative BCR value, whereas the sylvofishery had positive BCR value; meaning that sylvofishery system was profitable and feasible.
\end{abstract}

Keywords: BCR, mangrove, traditional extensive pond system, sylvofishery pond system

\begin{abstract}
ABSTRAK
Penurunan manfaat dari ekosistem mangrove baik secara langsung maupun tidak langsung disebabkan oleh konversi hutan mangrove menjadi tambak. Untuk mengembalikan kondisi lingkungan, pemerintah melakukan rehabilitasi tambak dengan menerapkan sistem tambak wanamina/sylvofishery. Penelitian ini bertujuan mengestimasi nilai eksternalitas kawasan mangrove yang dikonversi menjadi tambak di Delta Mahakam dan menghitung analisis usaha budidaya tambak dengan sistem ekstensif-tradisional serta sistem wanamina. Hasil penelitian menunjukkan nilai manfaat yang hilang mencapai Rp 209.688.551.071 per tahun dari hutan mangrove yang telah dikonversi menjadi tambak seluas 75.311 hektar. Nilai BCR tambak sistem ekstensif-tradisional menunjukan nilai negatif dan tambak sistem wanamina bernilai positif artinya bahwa pemanfaatan tambak dengan sistem wanamina akan mendatangkan keuntungan dan layak dilaksanakan pada saat ini.
\end{abstract}

Kata kunci: BCR, mangrove, tambak sistem ekstensif-tradisional, tambak sistem wanamina

\section{PENDAhULUAN}

Kerusakan hutan mangrove di Delta Mahakam disebutkan sekitar 85\% dari hutan mangrove yang ada akibat pembukaan tambak, pemukiman dan eksplorasi dan eksploitasi minyak dan gas
(Bosma et al., 2012). Pada tahun 2001, 75\% hutan mangrove telah dikonversi menjadi tambak (Zwieten et al., 2006). Bengen (2006) menyatakan bahwa dalam kurun waktu 20 tahun telah terjadi konversi mangrove sekitar 80.000 hektar, diantaranya sekitar 67.000 hektar dijadikan untuk 
tambak. Data terakhir (DKP Kukar, 2010) menunjukkan 75.311 ha kawasan Delta Mahakam telah dijadikan tambak dari sekitar kurang lebih 110.000 ha hutan mangrove di kawasan Delta Mahakam.

Sistem pertambakan di Delta Mahakam secara ekstensif tradisional dengan luas petak tambak lebih dari 2 (dua) hektar bahkan ada yang lebih dari 15 hektar mengakibatkan menambah besar kerusakan hutan mangrove. Data BPS Kutai Kartanegara (2010) menunjukan sekitar 7.874 hektar tambak telah tidak produktif dan ditinggalkan oleh petambak. Hal ini mengakibatkan kerusakan ekologi yang lebih parah lagi terhadap kawasan Delta Mahakam. Kerusakankeru-sakan itu antara lain (1) terjadinya erosi garis pantai dan sempadan sungai, (2) sedimentasi, (3) pencemaran, (4) berkurangnya fungsi ekologi dan ekonomi kawasan terutama penurunan produksi ikan tangkap maupun budidaya di Delta Mahakam (Bengen et al., 2011), dan (5) intrusi air laut hingga ratusan kilometer ke Kota Samarinda pada musim kering (Sidik, 2010).

Untuk mempertahankan dan pemulihan fungsi-fungsi ekosistem mangrove di Delta Mahakam sejak tahun 2000, dilaksanakan program rehabilitasi mangrove oleh berbagai pemangku kepentingan. Ada dua sasaran dari program itu yakni (1) rehabilitasi sempadan pantai dan sungai yang mengalami kerusakan, dan (2) penanaman mangrove pada tambak-tambak bagi pengembangan tambak wanamina (silvofishery). Penanaman mangrove untuk tambak dengan sistem wanamina tersebut dimulai dengan tambak wanamina percontohan dari PT. Total E \& P pada tahun 2003, yang menghasilkan panen udang 1 (satu) ton di lahan tambak seluas 2,3 ha. Tambak percontohan ini bertujuan mengajak petani tambak merubah sistem tambak tradisional mereka menjadi tambak wanamina karena menghasilkan produktifitas yang lebih tinggi dan juga dapat menghasilkan manfaat dari hutan mangrove berupa ikan alami yang lebih banyak di samping manfaat ekologi lainnya.

Keberhasilan sistem tambak wanamina dapat dilihat dari data KPH Purwakarta, yang menunjukkan bahwa dari luas areal mangrove seluas 14.535 ha dapat melibatkan sebanyak $4.342 \mathrm{KK}$ dalam kegiatan silvofishery. Kontribusi dari usaha budidaya tambak dengan luas total 208.000 ha dapat menghasilkan 129.279 ton ikan dan udang yang apabila ditaksir, nilainya melebihi dari $\mathrm{Rp}$ 138 milyar. Kegiatan ini pun dilaporkan dapat menyerap tenaga kerja sebanyak $117.034 \mathrm{KK}$ yang sudah barang tentu dapat memberikan penghasilan yang lebih baik bagi petani kecil (Fitzgerald \& Savitri, 2002). Menurut David \& Mirera (2008), peningkatan kesejahteraan masyarakat merupakan upaya yang sangat penting agar mereka dapat tetap menjaga ekosistem mangrove yang ada pada kawasan tersebut.

Beberapa penelitian terdahulu yang relevan menghitung hutan mangrove yang berubah fungsi lahan (konversi) menjadi tambak tumpang sari dan pemukiman, seperti penelitian dari Budiana (2005) dengan judul Valuasi Ekonomi Ekosistem Mangrove Berbagai Pola Tambak Tumpangsari pada Status Lahan Negara dan Lahan Milik (Studi Kasus: di Karawang - Jawa Barat), Suryono (2006) tentang Penilaian Ekonomi Lingkungan terhadap Konversi Hutan Mangrove menjadi Tambak dan Pemukiman (Studi Kasus: di Hutan Angke Kapuk Jakarta Utara) dan Azis (2006) dengan judul Analisis Ekonomi Alternatif Pengelolaan sistem Mangrove Kecamatan Barru Kabupaten Barru. Perbedaan penelitian ini dengan penelitian terdahulu adalah lebih terfokus untuk mengidentifikasi nilai eksternalitas pemanfaatan hutan mangrove menjadi pertamabakan.

Dengan kondisi ekosistem mangrove dan manfaat ekonomi tambak seperti dijelaskan sebelumnya, maka adanya analisis kelayakan kegiatan tambak wanamina menjadi sangat penting karena analisis ini akan mengasumsikan pelaksanaan tambak sistem tradisional yang telah dilaksanakan saat ini, dan merencanakan kegiatan usaha tambak tersebut apabila diterapkan tambak sistem wanamina pada seluruh kawasan. Perhitungan ini diharapkan akan lebih meningkatkan motivasi petambak dan membuktikan bahwa penerapan sistem ini secara ekonomi tetap menguntungkan. Tujuan dari penelitian ini adalah mengestimasi nilai eksternalitas akibat konversi mangrove menjadi tambak dan analisis usaha budidaya tambak dengan sistem ekstensif-tradisional dan sistem wanamina.

\section{METODOLOGI}

\section{A. Lokasi dan Waktu Penelitian}

Lokasi penelitian di Delta Mahakam yang termasuk pada posisi $117^{\circ} 15^{\prime}-117^{\circ} 40^{\prime}$ Bujur Timur dan $0^{\circ} 21^{\prime}-1^{\circ} 10^{\prime}$ Lintang Selatan, mencakup wilayah administrasi Kecamatan Anggana, Muara Jawa, dan Muara Badak, Kabupaten Kutai Kartanegara, Provinsi Kalimantan Timur. Waktu penelitian dilaksanakan selama 5 bulan, mulai bulan April 2012 sampai dengan Agustus 2012. 


\section{B. Pengumpulan Data}

Penelitian ini dilakukan dengan menggunakan metode survey. Penentuan rumah tangga responden dalam penelitian ini ditetapkan berdasarkan teknik Purposive Sampling, yaitu pengambilan sampel tidak secara acak melainkan berdasarkan pertimbangan jenis pemanfaatan. Metode ini digunakan untuk menilai manfaat langsung dan manfaat tidak langsung dari ekosistem mangrove. Responden yang mengambil manfaat langsung adalah petambak yang berada di sekitar ekosistem mangrove. Metode pengumpulan data melalui observasi dan wawancara di lapangan dilakukan untuk mengetahui kondisi ekonomi sosial masyarakat setempat.

\section{Eksternalitas}

Eksternalitas bisa positif atau negatif. Eksternalitas positif terjadi saat kegiatan yang dilakukan seseorang atau kelompok memberikan manfaat bagi individu atau kelompok lainnya, eksternalitas negatif adalah sebaliknya (Sankar, 2008).

\section{Eksternalitas positif}

Untuk mengetahui nilai eksternalitas positif dari pengembangan tambak pada ekosistem mangrove di Delta Mahakam, dilakukan perhitungan besar manfaat dan besarnya biaya. Kegiatan budidaya tambak merupakan bentuk opportunity cost dari lahan mangrove, karena konversi lahan mangrove menjadi tambak akan memberikan keuntungan dalam jangka pendek bagi petambak, tetapi kegiatan ini juga akan berdampak pada pemanfaatan mangrove lainnya, seperti penangkapan benur, kepiting dan lainnya.

\section{Eksternalitas negatif}

Adanya pengembangan tambak pada lahan mangrove, telah memberikan eksternalitas negatif berupa hilangnya nilai ekonomi ekosistem mangrove secara langsung dan tidak langsung.

\section{Manfaat yang Hilang secara Langsung}

Untuk analisis nilai manfaat ekonomi ekosistem mangrove yang mengacu pada Adrianto (2006), nilai ekonomi total manfaat ekosistem mangrove adalah sebagai berikut:

\section{Manfaat langsung (ML)}

Manfaat langsung yaitu manfaat yang diperoleh secara langsung dari ekosistem hutan mangrove yang terdiri dari manfaat langsung hasil hutan dan manfaat langsung perikanan. Manfaat langsung tersebut dapat diuraikan dalam persamaan:

a. Manfaat langsung hasil hutan(MLH)

$$
M L H=\sum_{i=1}^{n} H i
$$

Keterangan (Remarks): Hi = Manfaat langsung hasil hutan ke-i

b. Manfaat langsung perikanan (MLP)

$$
M L P=\sum_{i=1}^{n} P i
$$

Keterangan (Remarks): $\mathrm{Pi}=$ Manfaat langsung hasil perikanan ke-i

c. Secara keseluruhan, manfaat langsung dari pemanfaatan hutan mangrove dapat dituliskan sebagai berikut:

$$
\begin{aligned}
\text { ML }= & \text { MLH }+ \text { MLP } \\
\text { Keterangan (Remarks): } & \text { MLH }=\text { Manfaat Langsung Hasil } \\
& \text { Hutan, total hasil hutan seperti } \\
& \text { kayu bakar, bibit alam, kepiting } \\
& \text { dan lain-lain. } \\
& \text { MLP = Manfaat Langsung Peri- } \\
& \text { kanan, total hasil perikanan seperti } \\
& \text { kepiting, udang, ikan, dan lain- } \\
& \text { lain. }
\end{aligned}
$$

\section{Manfaat tidak langsung (MTL)}

Manfaat tidak langsung yaitu manfaat yang diperoleh dari suatu ekosistem hutan mangrove secara tidak langsung. Manfaat tidak langsung terdiri dari manfaat pengurangan pencemaran, penahan abrasi dan penyedia pakan alami, secara matematis dapat dituliskan sebagai berikut:

$$
\text { MTL }=\text { MTLpp }+ \text { MTLa }+ \text { MTLpa }
$$

Keterangan (Remarks): MTL $=$ Manfaat Tidak Langsung MTL pp = Manfaat Tidak Langsung pengurangan pencemaran MTL a $=$ Manfaat Tidak Langsung penahan abrasi MTL pa = Manfaat Tidak Langsung pakan alami

a. Manfaat tidak langsung pengurangan pencemaran

Nilai ini dapat diestimasi dengan menggunakan pendekatan replacement cost yang diaplikasikan untuk fungsi ekosistem mangrove sebagai pengurangan pencemaran. Biaya rehabi-litasi mangrove per hektar dapat digunakan sebagai replacement cost (Adrianto, 2004).

$$
\text { MTL pp }=\text { brm X } 1 \mathrm{tm}
$$

Keterangan (Remarks): MTL pp = Manfaat Tidak Langsung pengurangan pencemaran 
brm = biaya rehabilitasi mangrove
per hektar dengan jarak tanam 2,5
$\mathrm{x} 2,5 \mathrm{~m}$
$\mathrm{ltm}=$ luas total hutan mangrove
(ha)

b. Manfaat tidak langsung penahan abrasi

Untuk melakukan perhitungan kuantitatif fungsi hutan mangrove sebagai penahan abrasi digunakan metode proyek bayangan. Ketika suatu proyek memiliki dampak negatif, maka perlu dipikirkan adanya proyek-proyek bayangan beserta pembiayaannya yang dapat memberikan jasa pengganti guna mengimbangi hilangnya kekayaan lingkungan sebagai akibat proyek yang berjalan. Metode evaluasi ini digunakan untuk menduga nilai ekonomi dari suatu proyek atau pola pemanfaatan sumberdaya pesisir. Katakanlah jika tidak ada ekosistem mangrove, maka berapa besar biaya yang harus dikeluarkan untuk tanggul penahan gelombang (Harahab, 2010).

Acuan yang dipakai untuk menghitung seberapa besar biaya yang harus dikeluarkan untuk membuat tanggul guna mencegah abrasi mengikuti perhitungan Harahab (2010), adalah dari proyek Pemerintah Kota Pekalongan dalam membuat tanggul sebagai pencegah abrasi yang dikerjakan oleh PT. Saputra Adi Ajinugraha yang menghabiskan biaya Rp 900.000.000 dengan panjang $381 \mathrm{~m}$ dan tinggi $125 \mathrm{~cm}$ untuk daya tahan berjangka waktu 10 tahun, yang kemudian nilai ini dikonversikan untuk panjang garis pantai di Delta Mahakam yang terkena dampak abrasi.

c. Manfaat tidak langsung penyedia pakan alami

Ekosistem mangrove juga memberikan manfaat biologi, yaitu sebagai penyedia pakan alami bagi ikan, dengan menggunakan model regresi luasan ekosistem mangrove dan produksi udang yang diacu dari Naamin (1991), yaitu :

$$
\begin{aligned}
\mathrm{Y}=16,286 & +0,0003536 \mathrm{X} \\
\text { Keterangan }(\text { Remarks }): \mathrm{Y} & =\text { Produksi udang }(\mathrm{kg}) \\
\mathrm{X} & =\text { Luas ekosistem mangrove (ha) }
\end{aligned}
$$

\section{E. Analisis Usaha Budidaya Tambak}

\section{Net present value (NPV)}

Analisis ini merupakan selisih antara nilai sekarang (present value) dari manfaat dengan present value dari biaya, nilai NPV diperoleh dengan formula (Kadariah, 1978):

$$
N P V=\sum_{t=0}^{10} \frac{B t-C t}{(1+r)^{t}}
$$

Keterangan (Remarks): $\mathrm{B}_{\mathrm{t}}=$ Manfaat usaha pada tahun ke- $\mathrm{t}$ $\mathrm{C}_{\mathrm{t}}=$ Biaya usaha pada tahun ke- $\mathrm{t}$ $\mathrm{r}=$ Tingkat suku bunga $(12 \%$ per

$$
\begin{aligned}
& \text { tahun) } \\
& \mathrm{t}=\text { Umur proyek (10 tahun) }
\end{aligned}
$$

\section{Net benefit cost ratio (NBCR)}

NBCR adalah rasio jumlah nilai sekarang dari manfaat dan biaya. Kriteria alternatif yang layak adalah NBCR lebih besar dari 1 dan kita meletakkan alternatif yang mempunyai NBCR tertinggi pada tingkat pertama. Secara matematis, NBCR dapat disajikan sebagai berikut:

$$
N e t B / C=\frac{\sum_{t=0}^{n} \frac{B_{t}-C_{t}}{(1+r)^{t}}}{\sum_{t=1}^{n} \frac{B_{t}-L_{t}}{(1+r)^{t}}\left(B_{t}-L_{t}\right)}
$$

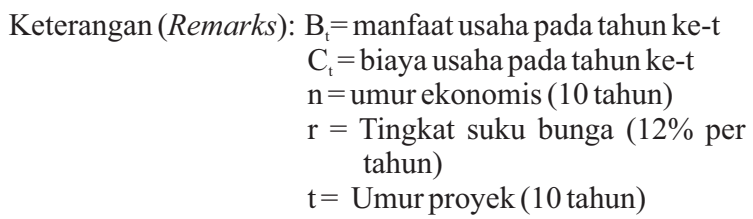

\section{HASIL DAN PEMBAHASAN}

\section{A. Penurunan Produksi Budidaya Tambak di Delta Mahakam}

Pada tahun 90-an hingga 2000 awal hasil udang sangat tinggi di kawasan Delta Mahakam baik itu di perikanan tangkap maupun budidaya, ada 5 (lima) cold storage yang menampung hasil udang untuk diekspor. Pada tahun 2008 hanya tinggal 1 (satu) cold storage yang beroperasi karena terjadi penurunan produksi udang di Delta Mahakam. Rachmawati (2003), mengatakan tambak di Delta Mahakam usia produktifnya adalah 5 (lima) tahun. Berdasarkan wawancara petani tambak di Delta Mahakam, mereka mengusahakan tambaknya hingga usia 10 tahun. Data menunjukkan terjadinya penurunan produktifitas tambak setelah umur 5 (lima) tahun (Tabel 1).

Berdasarkan penelitian Noryadi et al. (2006), pada tahun awal pembukaan tambak, produksi tambak antara 100-300 kg/ha/tahun, tetapi produksi menurun pada tahun ketiga-kelima sebesar $45 \mathrm{~kg} / \mathrm{ha} /$ tahun. Berdasarkan wawancara dengan petani saat ini, produktivitas menurun drastis dari sebelumnya, 3 ha bisa menghasilkan 1 ton setiap satu kali panen sekarang hanya mampu 50-100 $\mathrm{kg}$, dan panen hanya sekali atau dua kali setahun setelah 5 (lima) tahun umur tambak, hal ini sesuai dengan laporan tahunan Dinas Perikanan Kutai Kartanegara, yang menyebutkan setelah melewati umur lima tahun, produksi tambak untuk udang windu hanya menghasilkan $26 \mathrm{~kg} / \mathrm{ha} /$ tahun (Tabel 1). Angka ini jauh lebih rendah bila 
Tabel (Table) 1. Data produktivitas tambak di Delta Mahakam (Pond productivity data in the Mahakam Delta)

\begin{tabular}{|c|c|c|c|c|c|}
\hline \multirow{2}{*}{$\begin{array}{l}\text { Tahun } \\
\text { (Year) }\end{array}$} & \multirow{2}{*}{$\begin{array}{c}\text { Luas tambak } \\
\text { (Pond covers) } \\
\text { (ha) }\end{array}$} & \multicolumn{4}{|c|}{ Produksi (Production) (Ton) } \\
\hline & & Bandeng $^{\text {b) }}$ & Belanak $^{\text {a) }}$ & Windu $^{\text {b) }}$ & Lainnya $^{\text {a) }}$ \\
\hline 2003 & 22.111 & 1.365 & 402 & $2.976,5$ & $3.095,5$ \\
\hline Rata-rata/th/ha & & 0,062 & 0,020 & 0,135 & 0,140 \\
\hline 2009 & 75.311 & $2.618,7$ & $1.013,1$ & $1.851,9$ & $4.261,5$ \\
\hline Rata-rata/th/ha & & 0,035 & 0,013 & 0,026 & 0,056 \\
\hline
\end{tabular}

Sumber(Sources): Laporan tahunan Dinas Kelautan dan Perikanan, Kutai Kartanegara, 2003-2009 (The annual report of Department of Marine and Fisheries, Kutai Kartanegara, 2003-2009)

Keterangan (Remarks): $\left.{ }^{a}\right)$ Liar (wild), ${ }^{b}$ ) ditebar (spreaded)

dibandingkan dengan rata-rata tambak tradisional di Indonesia (600-1.000 kg/ha/tahun), (DKP, 2010).

Berdasarkan penelitian ini, ada banyak faktor yang menyebabkan produktivitas menurun, faktor utama adalah (a) tidak ada praktek terbaik dari sistem irigasi tambak (hanya 1 pintu air un-tuk inlet dan outlet/pemasukan dan pengeluaran), (b) penggunaan area yang luas dan (c) tidak ada pengelolaan dan pemeliharaan selama budidaya juga (d) usia tambak udang sudah sangat tua, umur tambak udang antara 15-25 tahun, sehingga lahan tambak udang tidak layak untuk budidaya udang karena kandungan pirit dan wabah penyakit yang sudah menyebar. Faktor lainnya adalah Karakteristik tanah tambak di Delta Mahakam sebagian besar adalah wilayah eks-Nypa, yang merupakan tanah sulfat masam ditandai dengan $\mathrm{pH}$ yang rendah, konsentrasi tinggi bahan organik dan pirit. Pengaruh $\mathrm{pH}$ tanah yang rendah menyebabkan fosfor tidak tersedia untuk pertumbuhan makanan alami karena diserap oleh besi dan aluminium. Penggunaan tambak secara terus menerus untuk budidaya akan menyebabkan menurunnya produktivitas udang karena daya du- kung lingkungan yang tidak mampu lagi menopang pertumbuhan (Abubakar, 2008).

\section{B. Eksternalitas Positif dari Konversi Hutan Mangrove menjadi Pertambakan}

Konversi hutan mangrove menjadi pertambakan akan berdampak pada kondisi ekonomi masyarakat di sekitarnya seperti penyerapan tenaga kerja dan peningkatan kesejahteraan masyarakat (Nurfiarini, 2003) dan sumbangan devisa yang besar dari ekspor udang bagi pendapatan asli daerah.

Berdasarkan hasil wawancara dengan masyarakat di kawasan Delta Mahakam, diketahui bahwa kegiatan budidaya tambak merupakan pekerjaan utama masyarakat dalam mencukupi kebutuhan hidup. Petambak berasal dari migrasi masyarakat pesisir Sulawesi Selatan yang berbondong-bondong membuka tambak pada tahun 1997-1998, karena harga udang sangat tinggi disebabkan oleh nilai tukar dollar yang tinggi terhadap rupiah akibat krisis moneter.

Perkembangan budidaya tambak di Kutai Kartanegara antara tahun 2005 sampai 2009 dapat dilihat di Tabel 2.

Tabel(Table) 2. Perkembangan budidaya tambak di Kutai Kartanegara antara tahun 2005-2009 (Pond aquaculture developments in Kutai Kartanegara in the years 2005-2009 period)

\begin{tabular}{ccccc}
\hline $\begin{array}{c}\text { Tahun } \\
(\text { Year })\end{array}$ & $\begin{array}{c}\text { Luas tambak } \\
\text { (Pond coverage) } \\
\text { (ha) }\end{array}$ & $\begin{array}{c}\text { Rumah tangga } \\
\text { perikanan (orang) } \\
\text { (Household fishery) } \\
\text { (person) }\end{array}$ & $\begin{array}{c}\text { Produksi } \\
\text { (Productivity) } \\
\text { (ton) }\end{array}$ & $\begin{array}{c}\text { Nilai (Value) } \\
\text { (x Rp 1000) }\end{array}$ \\
\hline 2005 & 32.111 & 2.875 & $8.786,5$ & 253.737 .700 \\
2006 & 32.111 & 2.875 & $8.804,1$ & 265.926 .000 \\
2007 & 39.000 & 3.100 & $9.860,5$ & 390.445 .000 \\
2008 & 52.117 & 3.210 & $9.939,9$ & 461.337 .600 \\
2009 & 75.311 & 7.272 & $11.279,0$ & 416.179 .850 \\
\hline
\end{tabular}

Sumber (Sources): DKP Kutai Kartanegara (2010) 
Dari Tabel 2 menunjukkan terjadi peningkatan trend luas tambak namun terjadi penurunan produksi tambak per hektarnya. Hal ini juga didukung oleh hasil wawancara berbagai pihak yang terlibat menyatakan telah terjadi penurunan produktivitas.

Berdasarkan wawancara dengan petambak yang memiliki rata-rata 4 (empat) hektar tambak maka dalam setahun, pada saat ini mereka hanya mampu menghasilkan pendapatan bersih sekitar 10 20 juta/tahun, sehingga tidak mencukupi untuk menghidupi keluarganya apabila berjumlah 3-5 orang.

\section{Eksternalitas Negatif dari Manfaat Lang- sung Ekosistem Mangrove}

Pendugaan dampak negatif dari manfaat langsung ekosistem mangrove berdasarkan pemanfaatan aktual pada tahun 2012 yang diidentifikasi sebagai nilai manfaat yang hilang akibat pengembangan tambak dapat dilihat pada Tabel 3 .

Tabel 3 menunjukkan bahwa dengan merubah hutan mangrove menjadi tambak pada ekosistem mangrove di Delta Mahakam, nilai manfaat langsung yang hilang mencapai Rp 143.090.900.000/ ha/tahun. Hal ini menandakan bahwa pemanfaatan langsung hutan mangrove telah menurun secara drastis akibat konversi hutan mangrove ke tambak.

\section{Eksternalitas Negatif dari Manfaat Tidak Langsung Ekosistem Mangrove}

Manfaat tidak langsung atau Indirect Use Value (IUV) adalah manfaat yang diperoleh dari ekosistem mangrove secara tidak langsung. Ekosistem mangrove di Delta Mahakam memiliki 2 (dua) jenis manfaat tidak langsung yang diidentifikasi sebagai nilai manfaat yang hilang akibat adanya pengembangan tambak yaitu manfaat fisik dan manfaat biologi.

\section{Manfaat sebagai penahan abrasi}

Acuan yang dipakai untuk menghitung seberapa besar biaya yang harus dikeluarkan untuk membangun tanggul guna mencegah abrasi adalah dari proyek Pemerintah Kota Pekalongan dalam membuat tanggul sebagai pencegah abrasi yang dikerjakan oleh PT. Saputra Adi Nugraha. Diperoleh data proyek pembuatan tanggul sebagai berikut: panjang $381 \mathrm{~m}$, tinggi $125 \mathrm{~m}$, biaya Rp 900.000.000, mampu bertahan 10 tahun, maka biaya pembuatan tanggul per meternya sebesar Rp 2.362.204,724 (Harahab, 2010). Dari asumsi itu, dapat dihitung berapa besar biaya yang harus dikeluarkan untuk membuat tanggul di Delta Mahakam dengan panjang pantai 53.501,68 $\mathrm{m}$, maka biaya pembuatan penahan abrasi dengan daya tahan 10 tahun seluruhnya mencapai $\mathrm{Rp}$ 126.381.921.260.

\section{Manfaaat sebagai pengurangan pencema- ran}

Standar biaya kegiatan Rehabilitasi Hutan dan Lahan dari Dana Alokasi Khusus Dana Reboisasi (DAK-DR) yang dilaksanakan oleh Kabupaten/Kota di Provinsi Kalimantan Timur untuk jenis tanaman mangrove adalah sebesar Rp -3.771 .000 , setiap hektarnya dengan jarak tanam $2,5 \times 2,5 \mathrm{~m}$. Seperti halnya untuk mendapatkan estimasi nilai sekarang, maka nilai tersebut dikonversi dengan rata-rata nilai inflasi yang terjadi pada tahun 2011 yaitu sebesar 6,6\%. Selanjutnya nilai konversi dikalikan dengan luas ekosistem mangrove yang harus direhabilitasi di Delta Mahakam seluas 75.311 ha, maka biaya rehabilitasi seluruhnya sebesar Rp 283.997.781.000.

Tabel(Table) 3. Nilai ekonomi ekosistem mangrove berdasarkan pemanfaatan langsung aktual pada tahun 2012 (The economic value of mangrove ecosystem based on actual direct use in 2012)

\begin{tabular}{|c|c|c|c|c|}
\hline No. & $\begin{array}{l}\text { Jenis } \\
\text { pemanfaatan } \\
\text { (Type of } \\
\text { utilization) }\end{array}$ & $\begin{array}{c}\text { Luas daerah } \\
\text { (Area coverage) } \\
\text { (ha) }\end{array}$ & $\begin{array}{l}\text { Nilai ekonomi } \\
\text { (Economic value }) \\
(\mathrm{Rp} / \mathrm{ha} / \mathrm{th})\end{array}$ & $\begin{array}{c}\text { Total nilai ekonomi } \\
\text { (Total of economic value) } \\
(\mathrm{Rp} / \mathrm{th})\end{array}$ \\
\hline 1 & Kayu bakar & 75.311 & 400.000 & 30.124 .400 .000 \\
\hline 2 & Kepiting & 75.311 & 8.000 .000 & 60.248 .800 .000 \\
\hline 3 & Benur & 75.311 & 7.000 .000 & 52.717 .700 .000 \\
\hline \multicolumn{4}{|c|}{ Total nilai manfaat aktual yang hilang } & 143.090 .900 .000 \\
\hline
\end{tabular}

Sumber (Sources): Data primer dan sekunder diolah (Primary and secondary data processed), 2012 


\section{Manfaat sebagai penyedia pakan alami}

Ekosistem mangrove juga memberikan manfaat biologi, yaitu sebagai penyedia pakan alami bagi ikan, dengan menggunakan persamaan Naamin (1991). Luas kawasan mangrove yang dikonversi menjadi tambak di Delta Mahakam adalah 75.311 ha. Dengan luasan ekosistem mangrove tersebut, diperoleh jumlah udang sebesar $42.916 \mathrm{~kg} / \mathrm{ha}$. Berdasarkan data aktual lapang, didapatkan harga pakan udang adalah Rp 14.000 per $\mathrm{kg}$ dan kebutuhan pakan 1,6 kg/ha per hari dengan 100.000 tebar benur. Berdasarkan data tersebut, maka nilai manfaat ekosistem mangrove sebagai penyedia pakan alami dengan mengalikan produksi udang dengan harga pakan dan kebutuhan pakan per ha, didapatkan nilai sebesar Rp 961.317,72 ha/tahun. Perbandingan nilai ekonomi ekosistem mangrove berdasarkan pemanfaatan tidak langsung aktual pada tahun 2012, ditunjukkan pada Tabel 4.

Pada Tabel 4, nilai ekonomi ekosistem hutan mangrove berdasarkan pemanfaatan tidak langsung tersebut merefleksikan preferensi individu atau masyarakat terhadap jasa-jasa lingkungan (ekosistem hutan mangrove). Jasa-jasa lingkungan sebagai perbaikan dan perlindungan kualitas hidup agar tetap baik (sebagai penahan abrasi, pengurangan pencemaran dan penyedia pakan alami) merupakan manifestasi dari kesediaan konsumen untuk membayar.

\section{E. Estimasi Total Nilai Eksternalitas ter- hadap Pengembangan Tambak pada Eko- sistem Mangrove di Delta Mahakam}

Estimasi nilai eksternalitas dapat bernilai positif dan negatif. Nilai eksternalitas positif dan negatif merupakan suatu upaya menilai manfaat yang diperoleh dari pemanfaatan sumberdaya dalam bentuk moneter. Berbagai kegiatan yang dilakukan oleh pemanfaatan sumberdaya akan menimbulkan eksternalitas, dalam hal ini adalah konversi hutan mangrove di Delta Mahakam untuk kegiatan yang terkait dengan perikanan budidaya yaitu tambak telah menimbulkan kerugian bagi petani tambak di Delta Mahakam saat ini. $\mathrm{Hal}$ ini dapat dilihat dari penurunan produksi, kenaikan biaya operasional dan perubahan harga, yang pada saat ini kegiatan budidaya tambak bila dibandingkan dengan fungsi hutan mangrove secara keseluruhan bagi kawasan Delta Mahakam juga menimbulkan kerugian yang besar seperti ditunjukkan pada Tabel 5 dan 6. Perhitungan nilai eksternalitas positif dan negatif yang diperoleh ditunjukkan pada Tabel 5.

Hasil analisis di atas, menunjukkan kegiatan pengembangan tambak pada ekosistem mangrove di Delta Mahakam telah memberikan nilai eksternalitas negatif sebesar Rp 209. 688.551.071 yang ditunjukkan pada Tabel 5, artinya kegiatan ini telah memberikan nilai kerugian yang cukup besar dari pada manfaat yang diperoleh. Penelitian lain yang telah dilakukan Koeshendrayana et al. (2009) dan Suryati (2012), menunjukkan hal serupa di Segara Anakan, produksi tambak telah mengalami penurunan dan kerugian besar terhadap lingkungan akibat konversi hutan mangrove menjadi tambak dalam beberapa tahun terakhir .

Analisis finansial tambak dengan sistim ekstensif-tradisional dilakukan untuk mengetahui kondisi terkini dari pengembangan tambak tradipsional di Delta Mahakam. Hasil analisis finansial untuk pengembangan tambak seluas 75.311 ha, menunjukkan dengan discount rate $12 \%$, mendapatkan Net Present Value (NPV) sebesar Rp -704.270.682.510 dan Benefit Cost Ratio (BCR) sebesar 0,37 sehingga tidak layak untuk diusahakan. Hal ini terjadi karena nilai manfaat ekosistem mangrove yang diidentifikasi sebagai nilai manfaat yang hilang atau biaya eksternal lebih besar dari pada nilai manfaat pengembangan tambak udang.

Tabel(Table) 4. Nilai ekonomi ekosistem hutan mangrove berdasarkan pemanfaatan tidak langsung aktual pada tahun 2012 (The economic value of mangrove ecosystem based on actual indirectuse in 2012)

\begin{tabular}{clcc}
\hline No. & $\begin{array}{c}\text { Jenis pemanfaatan } \\
\text { (Type of utilization) }\end{array}$ & $\begin{array}{c}\text { Nilai ekonomi } \\
\text { (Economic Economic) } \\
\text { (Rp/ha/th) }\end{array}$ & $\begin{array}{c}\text { Total Nilai Ekonomi } \\
\text { (Total of Economic value) } \\
(\mathrm{Rp} / \mathrm{th})\end{array}$ \\
\hline 1 & Penahan abrasi & $2.362 .204,724$ & 126.381 .921 .260 \\
2 & Pengurangan pencemaran & 3.771 .000 & 283.997 .781 .000 \\
3 & Pakan alami & $961.317,72$ & 72.397 .798 .811 \\
\hline \multicolumn{2}{l}{ Total nilai manfaat aktual yang hilang } & & 482.777 .501 .071 \\
\hline
\end{tabular}

Sumber (Sources): Data primer dan sekunder diolah (Primary and secondary data processed), 2012 
Tabel (Table) 5. Nilai eksternalitas ekosistem mangrove untuk masing-masing pemanfaatan (Externalities value of mangrove ecosystem for each utilization)

\begin{tabular}{lcc}
\hline \multicolumn{1}{c}{$\begin{array}{c}\text { Uraian } \\
\text { Description })\end{array}$} & $\begin{array}{c}\text { Rp/ha/tahun } \\
(\text { Rp/ha/year })\end{array}$ & $\begin{array}{c}\text { Rp/ha } \text { total luas tambak } \\
(\text { Rp/ha/Total pond covers })\end{array}$ \\
\hline $\begin{array}{l}\text { Positif/Pendapatan (1) } \\
\text { Manfaat Langsung } \\
\text { Tambak a }\end{array}$ & & \\
& & \\
Total 1 & $5.526 .149,57$ & 416.179 .850 .000 \\
& & \\
Negatif/Kerugian (2) & $5.526 .149,57$ & 416.179 .850 .000 \\
Manfaat Langsung & & \\
Kayu bakar & 400.000 & 30.124 .400 .000 \\
Benur & 7.000 .000 & 52.717 .700 .000 \\
Kepiting & 8.000 .000 & 60.248 .800 .000 \\
Jumlah sub 1 & 15.400 .000 & 143.090 .900 .000 \\
Manfaat Tidak Langsung & & $126.381 .921 .260^{\mathrm{c}}$ \\
Penahan abrasi & $2.362 .204,72^{\mathrm{b}}$ & 283.997 .781 .000 \\
Pengurangan pencemaran & 3.771 .000 & 72.397 .798 .811 \\
Penyedia pakan & $961.317,72$ & 482.777 .501 .071 \\
& & 625.868 .401 .071 \\
Jumlah sub 2 & $7.094 .522,44$ & \\
Total 2 & $22.494 .522,44$ & -209.688 .551 .071 \\
Total nilai eksternalitas & $28.020 .672,01$ & \\
$(1-2)$ & & \\
\hline
\end{tabular}

Sumber (Sources): Data Primer dan sekunder setelah diolah, 2012 (Primary and secondary data processed, 2012) Keterangan (Remarks): ${ }^{a}$ Data Produksi Tambak di Delta Mahakam, DKP Kukar (2010)

${ }^{b}$ Data tanggul pencegah abrasi per meternya sebesar Rp 2.362.204,724 (Harahab, 2010)

${ }^{c} \mathrm{Rp} 2.362 .204,724$ x panjang pantai Delta Mahakam sepanjang 53.501,68 m

'Total luas tambak 75.311 ha

\section{Analisis finansial usaha tambak}

Hasil analisis finansial budidaya tambak ekstensif-tradisional dan wanamina-tradisional, dengan beberapa asumsi sebagai berikut:

a. Proyek dilaksanakan ketika tambak ekstensiftradisional setelah umur 10 tahun, mengingat umur tambak produktif di Delta Mahakam adalah 10 tahun.

b. Tambak ekstensif-tradisional yang telah berumur 10 tahun dilakukan rehabilitasi menjadi tambak wanamina-tradisional.

c. Perbandingan analisis usaha ketika umur tambak ekstensif-tradisional dilanjutkan setelah sepuluh tahun dengan tambak wanaminatradisional dari program rehabilitasi.

d. Umur mangrove untuk tambak wanaminatradisional adalah 4 (empat) tahun ketika sudah menghasilkan serasah.

\section{Kelayakan usaha budidaya tambak sistem ekstensif-tradisional dan wanamina}

Untuk melihat kondisi terkini tambak ekstensif-tradisional yang masih diusahakan petambak dengan tambak ekstensif-tradisional yang telah direhabilitasi menjadi tambak wanamina tradisional di Delta Mahakam, dilakukan analisis kelayakan budidaya kedua sistem tersebut. Hasil analisis finansial berdasarkan wawancara responden pada tambak berumur di atas 10 tahun adalah:

a. Investasi di sini merupakan perbaikan tambak yaitu sebesar Rp 5.000.000 per ha

b. Biaya operasional sebesar Rp 6.310 .000 per hektar per tahun, lebih tinggi dari kondisi awal pembukaan tambak karena diperlukan pengolahan tanah lumpur tambak.

c. Penerimaan usaha diperoleh dari nilai produksi tambak berupa ikan, penerimaan sebesar Rp 9.600.000 per hektar per tahun. 
Hasil analisis finansial tambak sistem tradisional dengan discount rate $12 \%$, mendapatkan Net Present Value (NPV) sebesar Rp -1.710.000 dan Benefit Cost Ratio (BCR) sebesar 0,85. Hasil ini menunjukkan bahwa nilai NVP negatif dan BCR kurang dari 1 (satu) artinya bahwa pemanfaatan tambak dengan sistem tradisional akan mengalami kerugian dan usaha ini tidak layak dilaksanakan pada saat ini.

Hasil analisis usaha berdasarkan wawancara responden yang merubah sistem tambaknya menjadi sistem wanamina tradisional adalah sebagai berikut:

a. Investasi di sini merupakan perbaikan tambak yaitu sebesar Rp 20.000.000 per ha

b. Biaya operasional sebesar Rp 16.810 .000 per hektar per tahun

c. Penerimaan usaha diperoleh dari nilai produksi tambak berupa ikan, penerimaan sebesar Rp 48.000.000 per hektar per tahun

Hasil analisis finansial tambak sistem tradisional-wanamina pada tingkat suku bunga $12 \%$ mendapatkan Net Present Value (NPV) sebesar Rp 11.190.000 dan Benefit Cost Ratio (BCR) sebesar 1,30. Hasil ini menunjukkan bahwa nilai NVP positif dan BCR lebih dari 1 artinya bahwa pemanfaatan tambak dengan sistem wanamina akan mendatangkan keuntungan dan layak dilaksanakan.

Sebagian besar tambak yang ada di Delta Mahakam telah memasuki usia lebih dari 10 tahun dan tidak produktif lagi. Pemilik tambak banyak yang meninggalkan tambak-tambak yang tidak produktif lagi. Hal ini membuat permasalahan semakin rumit dalam memulihkan ekosistem mangrove karena mereka tidak tertarik lagi pada fungsi ekosistem mangrove dan produktivitas tambaknya. Pemulihan mangrove dapat dilakukan pemerintah dengan bantuan perusahaan-perusahaan migas di Delta Mahakam dengan merehabilitasi tambak-tambak mereka, merubah sistem tradisional menjadi sistem tambak wanamina yang berdasarkan analisis kelayakan dapat mendatangkan keuntungan bagi petani tambak dan memulihkan ekosistem mangrove, saat ini partisipasi masyarakat masih rendah karena sistem wanamina memerlukan investasi awal dengan dana yang besar berupa perbaikan tambak dan penanaman mangrove sehingga insentif dan bantuan dari pemerintah dan perusahaan-perusahaan migas sangat diperlukan untuk kesuksesan program tambak wanamina ini.

\section{KESIMPULAN DAN SARAN}

\section{A. Kesimpulan}

Pembudidayaan udang dengan sistem ekstensif-tradisional dengan mengkonversi hutan mangrove di Delta Mahakam telah mendatangkan kerugian yang besar pada saat ini. Hal ini dapat terlihat dengan perhitungan NVP sebesar $\mathrm{Rp}$ -704.270.682.510, dan nilai $\mathrm{B} / \mathrm{C}$ ratio sebesar 0,37 , yang berarti usaha tersebut sudah tidak layak.

Pengembangan pembudidayaan udang dengan sistem ekstensif-tradisional dapat dirubah ke sistem wanamina yang berdasarkan perhitungan menghasilkan NVP positif dan BCR lebih dari 1, sehingga sistem wanamina akan mendatangkan keuntungan dan layak dilaksanakan pada saat ini.

\section{B. Saran}

Solusi agar tambak-tambak yang sudah tidak produktif dan ditinggalkan petani tidak menimbulkan dampak lingkungan yang besar maka perlu dilakukan perubahan sistem tambak dari yang tradisional-ekstensif menjadi tambak sistem wanamina dengan dukungan penuh dari pemerintah dan perusahaan-perusahaan migas di sekitar kawasan Delta Mahakam, bisa berwujud pinjaman lunak, program pelatihan, atau penyediaan dana dari CSR (Corporate Social Responsibility) perusahaan-perusahaan migas.

\section{UCAPAN TERIMA KASIH}

Ucapan terima kasih disampaikan kepada Kementerian Pendidikan dan Kebudayaan (DIKTI dan DITLITABMAS), Republik Indonesia, dan Pemerintah Provinsi Kalimantan Timur untuk memberikan dukungan keuangan. Terima kasih juga disampaikan kepada Staf PT. Total Fina Elf Indonesia dan FPIK-FT UNMUL yang telah menyediakan data-data penelitian.

\section{DAFTAR PUSTAKA}

Abubakar. (2008). Efisiensi pengelolaan kawasan tambak udang dan dampaknya terhadap aspek ekonomi sosial dan ekologi di wilayah Pesisir Kabupaten Dompu. Bogor: Pascasarjana: Institut Pertanian Bogor. Disertasi. Tidak dipublikasikan. 
Adrianto, L. (2004). Ekonomi dan pengelolaan mangrove dan terumbu karang. Program Pascasarjana Ekonomi Sumberdaya Kelautan Tropika: Pusat Kajian Sumberdaya Pesisir dan LautanIPB. Institut Pertanian Bogor. pp 54-59.

Adrianto, L. (2006). Pengenalan konsep dan metodologi valuasi ekonomi sumberdaya pesisir dan laut sinopsis. PSPL. Bogor: Institut Pertanian Bogor.

Azis, N. (2006). Analisis ekonomi alternative pengelolaan sistem mangrove kecamatan barru kabupaten barru. Tesis. Tidak diterbitkan. Bogor: Institut Pertanian Bogor.

Badan Perencana dan Pembangunan Daerah Kutai Kartanegara. (2003). Rencana detail tata ruang kawasan Delta Mahakam. Kerjasama antara Bappeda Kutai Kartanegara dengan LAPI Institute Teknologi Bandung. Tenggarong.

Badan Perencana dan Pembangunan Daerah Kutai Kartanegara. (2010). Rencana rehabilitasi dan konservasi mangrove di Delta Mahakam Kabupaten Kutai Kartanegara, Kalimantan Timur. Tenggarong.

Bengen, D.G., Widiarso, D., Ibrahim, M., \& Arif, M. (2011). Mangrove Delta Mahakam. Bogor: Penerbit P4L.

Badan Pusat Statistik Kutai Kartanegara. (2010). Kutai Kartanegara dalam Angka 2009. Tenggarong.

Bosma, R., Sidik, A.S., Van Zwieten, P.A.M., Aditya, A., \& Visser, L. (2012). Challenges of a transition to a sustainably managed shrimp culture agro-ecosystem in the Mahakam Delta, East Kalimantan, Indonesia. Wetlands Ecology and Management, 20(2), 88-99.

Budiana, A. (2005). Valuasi ekonomi ekosistem mangrove berbagai pola tambak tumpang-sari pada status lahan negara dan lahan milik (Studi kasus: di Karawang-Jawa Barat) Tesis. Tidak diterbitkan. Bogor: Institut Pertanian Bogor.

Departemen Kelautan dan Perikanan Kutai Kartanegara. (2010). Statistik Perikanan 2009. Tenggarong, Indonesia.

David, H., \& Mirera, O. (2008). Enhancing mangrove wetland conservation through silvofisheries opportunities in two coastal communities, kenya. Final Report. Rufford Small Grants Program.

Fitzgerald, B., \& Savitri, L.A. (2002). Integration of silvofisheries into coastal management and mangrove rehabilitation in Java Indonesia. Food and Agriculture Organization (FAO), the World Bank Group, World Wildlife Fund (WWF), and the Network of Aquaculture Centres in Asia-Pacific (NACA).
Harahab, N. (2010). Penilaian ekonomi ekosistem hutan mangrove dan aplikasinya dalam perencanaan wilayah pesisir. Yogyakarta: Graha Ilmu.

Naamin, N. 1991. Penggunaan hutan mangrove untuk budidaya tambak keuntungan dan kerugian. Prosiding Seminar IV Ekosistem Hutan Mangrove MAB Indonesia LIPI. Bandar Lampung.13 -14 Mei 1991.

Noryadi, Bambang, I.G., Maidie, A., Suyatna, I., \& Sidik, A.S. (2006). Studi produktifitas tambak di delta mahakam. Kalimantan Timur. FPIK: Universitas Mulawarman, Samarinda.

Nurfiarini, A. (2003). Kajian pengembangan budidaya perikanan pesisir dan pengaruhnya terhadap kondisi sosial ekonomi masyarakat di Teluk Saleh Kabupaten Dompu. Pascasarjana. Institut Pertanian Bogor. Tesis. Tidak dipublikasikan.

Kadariah. (1978). Pengantar evaluasi proyek. Fakultas Ekonomi: Universitas Indonesia. Jakarta: Penerbit L.P.

Koeshendrajana, S. (2009). Riset identifikasi, karakterisasi, valuasi sosial-ekonomi sumberdaya pesisir. Laporan Teknis. Balai Besar Riset Sosial Ekonomi Kelautan dan Perikanan. Jakarta: Badan Riset Kelautan dan Perikanan, DKP.

Rachmawati. (2003). Nilai ekonomi mangrove dan kepedulian masyarakat terhadap mangrove di Delta Mahakam. Jakarta: PPK-LIPI.

Sankar, U. (2008). Environmental eksternalities. Akses tanggal 2 Februari 2015, dari: http//coe.msc. ac.in/dp/envt-ext-sankar.pdf.

Sidik, A.S. (2010). The changes of mangrove ecosystem in Mahakam Delta, Indonesia: A Complex social - Environmental pattern of linkages in resources utilization. Borneo Research Journal, 4, 27-46.

Suryati, S.H. (2012). Model resiliensi masyarakat di Laguna Segara Anakan. Pascasarjana: Institut Pertanian Bogor. Disertasi. Tidak dipublikasikan.

Suryono, T. (2006). Penilaian ekonomi lingkungan terhadap konversi hutan mangrove menjadi tambak dan pemukiman. Tesis. Tidak dipublikasikan. Institut Pertanian Bogor.

Van Zwieten, P.A.M., Sidik, A.S. Noryadi, Suyatna, I., \& Abdunnur. (2006). Aquatic Food Production in the Coastal Zone: Data-based Perceptions on the Trade-Off between Mariculture and Fisheries Production of the Mahakam Delta and Estuary, East Kalimantan, Indonesia. In: Hoanh C.T., Tuong T.P., Gowing J.W., Hardy B. (eds) Environmental and Livelihoods in Tropical Coastal Zones: Managing Agriculture-Fishery-Aquacultue Conflicts (pp. 219236). CABI, Oxfordshire. 